\title{
LA FORMACIÓN CIUDADANA EN LA ESCUELA: EDUCANDOS CRÍTICOS Y ACTIVOS (Citizenship education at school: students and critical assets)
}

Fecha de recepción: II febrero de 2016

Fecha de aceptación: 20 abril de 2016

Encuentre este artículo en

http://biblioteca.uniminuto.edu/ojs/index.php/IYD/issue/archive

Para citar este artículo / To cite this article.

Ripoll-Rivaldo, M - Ripoll Rivaldo, A - Vásquez -Rizo, F (2016). La

formación ciudadana en la escuela: educando críticos

y activos. Revista Inclusión \& Desarrollo, 3 (I), 24-33
María Ripoll Rivaldo mripollriva@uniminuto.edu.co.

Antonio Ripoll Rivaldo ${ }^{2}$ mripollriva@uniminuto.edu.co

Fredy Eduardo Vásquez Rizo 3 fvasquez@uao.edu.co

Resumen

Resulta notoria la importancia que en estos momentos ha adquirido la formación ciudadana en la educación, pues es mucho lo que se plantea y se debate en torno al tema; es por ello que, a través de este artículo, se intenta participar de dicha discusión, presentando una reflexión sobre el papel que podría asumir la escuela de hoy en la formación ciudadana, haciendo énfasis en la importancia del estudiante como ciudadano del presente y del futuro, y el papel de la pedagogía como orientadora de dicha formación para la escuela y para la vida. Se evidencia, además, desde este espacio, la necesidad de estrechar la relación escuela-estudiante buscando la formación de individuos activos, críticos y socialmente responsables y competentes, que puedan desenvolverse de manera protagónica y consciente en la sociedad a la que pertenecen.

Palabras clave: ciudadanía, currículo, formación, pensamiento crítico, pedagogía, conocimiento.

Abstract

It is remarkable the importance that currently has acquired the citizenship training in education; since there have been a lot of ideas and discussions around the subject. That is why, through this article is intended to have a stake in this discussion, presenting a reflection on the role to be played today by the school in the civic training, emphasizing the importance of the student as a citizen of present and future and the role of pedagogy as a guide for such training for school and for life. Furthermore, it is noticed, from this perspective, the need to bridge the gap between schoolstudent looking for educability of, critical, socially responsible and competent individuals who can cope through a leading and conscious role in society where they belong to.

Keywords: citizenship, curriculum, training, critical thinking, pedagogy, knowledge.

'Estudiante del Programa de Psicología de la Institución Universitaria Politécnico Grancolombiano, magíster en Ciencias de la Educación de la Universidad Simón Bolívar y licenciada en Ciencias de la Educación con énfasis en Ciencias Sociales de la Universidad del Atlántico, Colombia. Actualmente se desempeña como maestra coinvestigadora del programa "Ondas Atlántico", en las líneas Ciencias Sociales y del Comportamiento, Pedagogía y Educación, y es integrante del Grupo de Investigación Desarrollo Social y Gerencial adscrito a la línea Innovación Educativa y Transformación Social de la Corporación Universitaria Minuto de Dios -UNIMINUTO.

${ }^{2}$ Estudiante de la Maestría en Gestión de la Tecnología Educativa de la Universidad de Santander, Colombia; Especialista en Administración de la Informática Educativa de la Universidad de Santander, e Ingeniero Químico de la Universidad del Atlántico, Colombia. Fue tutor del programa "Todos a Aprender en Bolívar". Actualmente se desempeña como docente investigador del Instituto Técnico Distrital Cruzada Social.

${ }^{3}$ Estudiante de Doctorado en Gestión de la Información y de la Comunicación en las Organizaciones de la Universidad de Murcia, España; magíster en Ciencias de la Información y Administración del Conocimiento del Instituto Tecnológico de Estudios Superiores de Monterrey -ITESM, México, y comunicador social-periodista de la Universidad Autónoma de Occidente, Colombia. Actualmente se desempeña como coordinador del Sistema de Información de la Oficina de Planeación y Desarrollo Institucional de la Universidad Autónoma de Occidente; coordinador del Grupo de Investigación en Gestión del Conocimiento y Sociedad de la Información, y es integrante del Grupo de Investigación en Educación. 


\section{INTRODUCCIÓN}

a sociedad del siglo XXI, enmarcada en la sociedad - de la información y del conocimiento y vista como una "aldea global", según McLuhan y Powers (2002), pone de manifiesto que el elemento esencial de transformación actual o de construcción social debe estar centrado en el conocimiento y en la educación, siendo esta última reconocida como un factor posibilitador de la convivencia, promotor de la tolerancia y facilitador de la participación ciudadana.

En este sentido, se vislumbra una estrecha relación entre la educación (el sistema educativo) y la formación ciudadana ${ }^{4}$, la cual debe permitir y garantizar la inclusión del sujeto educado en el ámbito social y ciudadano, de tal forma que este asuma sus deberes, goce de sus derechos, cumpla con las leyes y participe activamente en los asuntos públicos de la comunidad a la cual pertenece.

Para ello es necesario que dicho sujeto, a través de la educación, desarrolle un conjunto de habilidades y competencias sociales que le permitan desenvolverse de la mejor forma posible en la vida misma, de manera voluntaria, racional y con principios éticos y axiológicos, asumiendo con responsabilidad los constantes cambios planteados en el medio en que habita. Ser competente implica saber interpretar el medio en el que el alumno interactúa, proponer alternativas y ser capaz de argumentar, operaciones que requieren de unos conocimientos sobre cómo es y cómo funciona la sociedad, y qué consecuencias han tenido y tienen las acciones que realizan las personas y los colectivos (Gómez, Miralles y Molina, 2015).

Lastimosamente, muchos de estos individuos (estudiantes), hoy por hoy, muestran algún tipo de resistencia o apatía frente a la puesta en práctica de las reglas formales (normas legales establecidas en los manuales de convivencia de las instituciones educativas, reglamentaciones y leyes vigentes, etc.) y miran con indiferencia el papel de las reglas informales (morales y sociales), situación que trae como consecuencia un comportamiento cada vez más díscolo, intolerante, agresivo, irrespetuoso y discriminativo.

Es por esto que se hace absolutamente necesario, desde la escuela como protagonista del proceso básico formativo del individuo, instaurar procedimientos pedagógicos de formación ciudadana, en los que exista una total relación entre lo eminentemente pedagógico y el componente curricular, planteando y asumiendo un reordenamiento, una reestructuración epistemológica, de los principios sobre los cuales se organizan los actuales planes de estudio.

De igual manera, se propone asumir un modelo pedagógico, un proyecto formativo y hasta una directriz misional, a través de los cuales el acto de educar implique un compendio de elementos posibilitadores de la formación de ciudadanos críticos, activos y conscientes, en el marco de un proceso de escolarización que permita conocer, comprender y construir el conocimiento suficiente para actuar, no solo responsablemente en sus labores educativas, sino también en la vida cotidiana de forma competente.

Con base en lo anterior, el presente artículo hace un llamado para que en las instituciones educativas, especialmente las que tienen a su cargo la formación inicial del individuo, se tome conciencia acerca de la importancia de la conjunción entre la educación tradicional y la formación ciudadana, ya que es imperativa una articulación entre los diferentes ciclos que atraviesa el educando, para brindarle las herramientas suficientes y necesarias en su desenvolvimiento social, ya que, si bien la familia y la comunidad son actores importantes, es la escuela la llamada a ser el escenario perfecto para que el proceso de socialización del sujeto ocurra y se pueda desarrollar su madurez moral (entendida esta como un factor determinante para superar el subjetivismo y ponerse en el lugar del otro, en función de una posible transformación social).

\section{LA ESCUELA: ESCENARIO POR EXCELENCIA PARA LA FORMACIÓN CIUDADANA}

Como queda en evidencia, la escuela debería ser el lugar designado para promover, promocionar y fortalecer las competencias ciudadanas. Es por ello que un centro escolar necesita propender por la democracia, la participación y la justicia, elementos que constituyen los ejes del desenvolvimiento social; por lo tanto, la institución educativa tiene que fungir como un escenario en el que se inculquen los valores a través de

${ }^{4}$ Entendida esta, según Zambrano et al., (2014) como el conjunto de conocimientos y capacidades que el individuo debe desarrollar para que le permitan tomar conciencia individual y colectiva sobre sus actitudes y acciones en un contexto determinado, teniendo como referencias la ley y sus principios morales y religiosos, para conseguir la realización de su ser, en el instante que escucha, se comunica e interactúa con el otro y respeta la naturaleza. 
la orientación activa y responsable de sus docentes y funcionarios.

Lastimosamente, no siempre las instituciones de educación son conscientes de tamaña responsabilidad y muchas veces dejan en manos de otros esta misión formativa, sucumbiendo, en muchos casos, a intereses difusos (ideológicos, monetarios o de otro tipo), que impiden el desarrollo correcto del que debería ser uno de sus principales pilares: la formación integral del sujeto.

Por lo anterior, es fundamental que la escuela se concientice de su papel protagónico y asuma un compromiso real para consigo misma y para con sus educandos, de modo que sus actividades se enfoquen en una mejor comprensión e implementación de las competencias ciudadanas, pues el modelo educativo actual ya no se supedita solo a lo que el maestro le pueda entregar al alumno, sino que se caracteriza por proponer una multiplicidad de caminos para llegar al conocimiento, permitiendo que dichas competencias se conviertan en un elemento crucial para la resolución de problemas concretos y para suplir las necesidades de un nuevo orden social, cambiante, diverso y heterogéneo (Mora et al., 2009).

Es por ello que, al hablar de la formación de competencias ciudadanas, se está haciendo referencia (directa o indirectamente) a un cúmulo de sectores y factores recíprocamente influyentes en el individuo y en su entorno, cuya relación necesita de bases sólidas para poder armonizar la cantidad de variables circundantes, encaminadas a hacer frente a los diversos actores sociales, a sus subjetividades, a sus múltiples entornos (institucionales, comunitarios, grupales, organizacionales, etc.), a sus necesidades y problemas, y a todos aquellos elementos que hacen del contexto humano una maraña de estratagemas.

Es que cuando se habla de este tema, es necesario comprender que el sentido moral de la práctica ciudadana no debería limitarse solo al sujeto, sino que se debería considerar también a la sociedad de la cual forma parte -cómo este sujeto la impacta y cómo esta impacta al sujeto- y las normatividades individuales y colectivas vigentes, pues solo así se podrán formar individuos y edificar sociedades acordes con las verdaderas necesidades humanas actuales (Restrepo y Echavarría, 2013).

Y es aquí cuando todos los estamentos que intervienen en la formación del sujeto deben entrar a participar, en una acción mancomunada, siendo guiados por la misma escuela; por lo que esta debe cumplir inteligentemente consulabor, promoviendo, através dela educación, las competencias ciudadanas, convertidas en un aspecto transversal a todas las acciones del individuo. Para Mora et al., (2009), la formación académica de hoy debe promover el desarrollo de competencias, lo cual es mucho más complejo que la simple transmisión de conocimientos, pues debe consistir en enseñar el saber hacer (de manera consciente), lo que implica no solo la aprobación, validación e implementación de un currículo, sino la aplicación de los conocimientos que este contiene en circunstancias prácticas y cotidianas de la vida.

\section{LA ÉTICA Y LA MORAL DENTRO \\ DE UNA NUEVA EDUCACIÓN}

\section{PARA LOS NUEVOS CIUDADANOS}

Es importante que, en el marco de esta nueva educación ciudadana propuesta, no se deje de lado la dimensión ética, vista como una característica propia del obrar moral del sujeto; es decir, que la moral sea un elemento siempre presente en cada una de las acciones que se realicen. En este sentido, un ciudadano, como el que aquí se propone, formado por una nueva escuela, sin desconocer la familia y la comunidad a la cual pertenece, necesita ser un individuo ético, característica que lo hace humano, legal, íntegro, virtuoso y justo.

Se hace énfasis en esto porque, como bien puntualiza Cortina (2002), el sujeto de hoy es una persona con una gran desmotivación y desinterés moral, y displicente a la hora de promover y practicar las normas establecidas. Entonces, icómo lograr que el estudiante actual se interese y se motive por asumir una correcta conducta moral, en el marco de la formación en competencias ciudadanas? La respuesta, basada en Hobbes (1999), consiste en cimentar y construir dicha moral, y la conciencia de ella, desde la escuela, convenciendo al sujeto de que su implementación, aplicación y seguimiento es en beneficio de sí mismo y de todo su entorno.

Por ello, la educación que se imparta desde la escuela deberá promover el componente ético, entendido este como la esencia del espíritu ciudadano, cimentado en los preceptos de los derechos humanos y en la aplicación de los principios y valores que regulan todo actuar, incluyendo los preceptos morales, pues, según Westbrook (1999), constituye la única base verdadera de una conducta moral como práctica democrática y social. En el mismo sentido, en este artículo se plantea una formación ética aplicada a las actividades diarias, con 
elementos prácticos y ejemplos concretos, convertida en un componente inherente e indeclinable del nuevo ciudadano, del nuevo estudiante, del nuevo sujeto y del nuevo modelo de formación.

En esta dirección, De La Rosa (1977) plantea que los objetivos perseguidos con la educación cívica deben estar encaminados hacia la formación del estudiante como individuo ético y como ser social; por ello, propone que en un estudiante que se forme en la competencia ciudadana se debe:

- Permitir el desarrollo de su espíritu crítico, al posibilitarle elegir, discernir y opinar sobre cuestiones concretas.

- Estimular la sociabilidad y el esfuerzo conjunto a través del trabajo en equipo.

- Fomentar el sentido de responsabilidad compartida.

- Incitar a la vida social a través de las relaciones que se establecen con unidades sociales básicas distintas a la escuela y a la familia.

- Propiciar la hermandad entre los hombres y la búsqueda de la paz mediante las relaciones con personas diferentes a los compañeros de clase, procedentes de otras localidades e incluso de países diferentes.

- Contribuir a la búsqueda de la verdad con el contraste de criterios y los debates necesarios para el planteamiento y la solución de cuestiones de interés comunitario.

A partir de lo anterior, se puede apreciar que la ética ciudadana pretende, ante todo, formar hombres y mujeres desde su actuar e intelecto, con valores y conocimientos en ciudadanía; y es aquí cuando los lineamientos de la educación necesitan sentar las bases y brindar las herramientas para que esto suceda, ya que su objetivo debe ser formar personas de indeclinable espíritu social y de virtudes y valores cívicos, en el marco de una excelente preparación académica.

Un aporte al respecto, desde la investigación en educación, lo constituye un estudio realizado por Torney Purta et al. (|99|), quienes examinaron en veintiocho países la calidad de la educación cívica impartida; sin embargo, identificaron solo dos elementos comunes: la obediencia a la ley y el compromiso con la discusión política, lo que pone en evidencia la inexistencia de acuerdos generales concretos sobre el tema y de un interés definido, por parte de la pedagogía, en lo ético y lo moral. Esta situación se debe asumir como una invitación para empezar a trabajar desde lo local sobre esta temática, asumiendo un compromiso de transformación social basado en la formación de ciudadanos comprometidos con su accionar ético y moral, y con su participación colectiva.

Desde esta realidad se puede decir, entonces, que la educación en ciudadanía necesita fundamentarse en la esencia misma del sujeto, cuyos valores y principios sean los que conduzcan su accionar. Al respecto, Cortina (2009) afirma que solo de esta forma, desde el actuar individual, es que se puede llegar a impactar y transformar el conjunto llamado sociedad, y es desde dicha ética específica que se construye el ciudadano que tanto reclama la sociedad, aquel que debe ser el producto edificado de un proceso formativo de calidad.

Lo anterior tiene una relación directa con la "ética del desarrollo", expuesta por Villarroel (2013), la cual consiste en una reflexión crítica sobre los fines y medios que definen a los cambios sociales, económicos y culturales en los países y regiones en vía de desarrollo, lo que permite enfatizar en el rol activo que cumple el concepto ético-moral en el desarrollo mismo de los sujetos y del conjunto social que conforman (Crocker, 2008).

Es por esto que la formación ciudadana tiene que ser un proceso innegociable desde el punto de vista pedagógico, pues es la herramienta que le permitirá al individuo formado solucionar sus problemas, presentes y futuros, mediante el diálogo, la capacidad de ponerse en el lugar del otro y el entendimiento y la comprensión de manera consciente de su realidad.

Al respecto, el Ministerio de Educación Nacional MEN (2006) expresa:

(...) El énfasis de la formación en competencias ciudadanas es el desarrollo integral humano que implica el desarrollo de competencias comunicativas, cognitivas, emocionales e integradoras, las cuales favorecen el desarrollo moral (p. 156).

(.. .) La mejor manera de promover las acciones que queremos desarrollar es vivirlas cotidianamente en la escuela; a su vez, un modo efectivo de promover valores es aplicarlos allí mismo. En todas las áreas se pueden proponer actividades, reflexiones y discusiones valiosas (p. 162).

Los seres humanos, conscientes de las dificultades de la vida en la sociedad, han establecido unos acuerdos de suma importancia (...) para promover y proteger los principios básicos de la vida armónica en sociedad. Estos 
grandes acuerdos conforman el horizonte de formación de las competencias ciudadanas.

El más significativos de estos acuerdos es la Declaración Universal de los Derechos Humanos ( $p$. $|5|)$.

El otro, no menos importantes, es la Constitución Política de Colombia: norma de normas. Las grandes metas de la formación en competencias ciudadanas están ligadas a los derechos y deberes que todos tenemos como Colombianos, que buscan aportar para construir la paz, fomentar la participación democrática y valorar la pluralidad.

Teniendo en cuenta lo planteado anteriormente, la formación ciudadana debe ser de carácter integral y las escuelas tienen que brindar contenidos pertinentes al mundo de hoy. Al respecto, Zapata y Villa (2010) consideran que la formación integral debe estar sustentada en una concepción de todas las dimensiones del hombre en su conjunto, en la potencialidad del ser humano, social, ético y político, desde una mirada antropológica, social y cultural, que posibilite que el conocimiento se dirija a su pleno desarrollo y permita condiciones de equidad, justicia, paz y libertad para convivir con los demás.

Lastimosamente, si bien la Unesco, a través del Centro para la Formación en Derechos Humanos, Ciudadanía Mundial y Cultura de Paz, trabaja en el tema creando una conciencia de ciudadanía mundial activa para que hombres y mujeres sean capaces de cimentar sus vidas y dirigir su conducta fundamentándose en el respeto a los derechos humanos, la cultura de paz y los valores universales ${ }^{5}$, en Colombia se han incorporado en algunos de los planes de estudio de la educación básica, media y superior -área Ciencias Sociales-cursos sobre democracia, Constitución Política, cultura de la legalidad, convivencia ciudadana y cátedra de la paz en trámite-, y se han generado y promovido, desde el Ministerio de Educación Nacional -MEN, documentos sobre dicha formación; no obstante, aún los esfuerzos no son suficientes para que toda la comunidad estudiantil se concientice y se forme en el tema.

Es por esto que el texto aquí propuesto pretende convertirse en un insumo y en un llamado de atención para que las instituciones de educación se responsabilicen de la incorporación e implementación, en sus planes de trabajo y diaria labor, de actividades relacionadas con esta trascendental temática, en beneficio de toda una sociedad.

\section{LA REALIDAD SOCIAL QUE CIRCUNDA}

\section{AL ESTUDIANTE DE HOY}

Actualmente la educación atraviesa tiempos difíciles, teniendo que enfrentarse a una sociedad cambiante y acelerada que la desafía constantemente. Uno de estos desafíos lo constituyen los educandos, quienes son un reto para las prácticas educativas vigentes (Bauman, 2009), pues el ritmo frenético en el que viven contrasta con la velocidad, a veces aletargada, con que los docentes imparten sus clases; además se evidencia un divorcio entre el modelo pedagógico y la labor en el aula.

Por ello, los docentes y las instituciones de educación no pueden quedar rezagados en el marco de este nuevo escenario formativo, máxime si se está hablando de competencias ciudadanas, pues de ellos depende la calidad de la educación que se imparta y su impacto en la sociedad.

Al respecto, Flórez (2000) afirma que el docente de hoy, específicamente el que viene aplicando y trabajando modelos educativos "antiguos" -y que en muchos casos se niega a cambiar-, maneja tiempos muy distintos a los de su estudiante, situación que propicia que ambos asuman posturas dubitativas, de indeterminación, de incertidumbre y de azar, que finalmente atentan contra el proceso formativo mismo y repercuten negativamente en el actuar social del sujeto formado; de allí que sea fundamental que la escuela y el docente se preocupen por formarse en las nuevas $y$ cambiantes funciones tutoriales, ya que es la única forma de garantizar la adquisición de las nuevas competencias requeridas por parte del estudiante (Aguilar et al., 2015).

Es por esto que, para poder formar ciudadanos hoy, la escuela y educando necesitan estar abiertos a la posibilidad de existencia de diferentes frentes socioculturales y de distintos ritmos y caminos de enseñanza-aprendizaje, los cuales, en menor o mayor medida, afectan el proceso formativo y de socialización (Ripoll y Méndez, 20II). Tal es el caso de Colombia, donde las representaciones y los imaginarios sociales reafirman que existe una serie de problemáticas colectivas e individuales que durante décadas han promovido confusos y errados modelos de formación -incluyendo el modelo de formación ciudadana-,

${ }_{5}^{5}$ Solidaridad, honradez, libertad y respeto (Delors, 1996). 
los cuales han desarrollado diversos paradigmas y esquemas mentales, muy distantes de los ideales, que han ocasionado que la labor de la academia sea mucho más titánica e, incluso, infructuosa.

Factores como la corrupción, la violencia, la delincuencia, el tráfico de drogas, el debilitamiento del Estado -incluso en la ética de la responsabilidad social, cuyos vacíos deben ser cubiertos por el propio ciudadano (Ortiz, 20l4)-, la ineficacia del aparato judicial y la exclusión, entre muchos otros, han llevado a que los jóvenes piensen y sientan que lo ético y lo moral no tienen sentido. Esta situación se evidencia en las redes sociales, en las que aparecen fuertes indicios de descomposición con respecto a la moral y la ética: matoneo escolar, comentarios vulgares, fotos obscenas, ridiculización de personas, plagio, etc., producto de la suplantación del rol formador de la escuela, el cual se ha visto contaminado y sustituido por factores externos, no pedagógicos, a los cuales el estudiante tiene acceso en todo lugar y momento (televisión, Internet, etc.), situación que ha generado el surgimiento de una especie de cultura amoral o antiética.

De Oliveira (2014) se refiere a esta situación afirmando que han cambiado tanto los valores morales en los jóvenes que dicha transformación ha incidido negativamente en sus comportamientos -físicos y sicológicos-, muchos de ellos tornándose violentos, obligando a la escuela a repensarse desde la ética para contestar ciertas preguntas: icómo pensar la ética en la escuela desde un punto de vista argumentativo y no dogmático?, iqué desafíos se deben enfrentar en la educación ética de los estudiantes en el contexto de la escuela actual?

Por ello, es menester de la escuela retomar su rol formativo protagónico, asumirlo con responsabilidad y brindarle herramientas e insumos al educando para que retome el camino ético y constructivo en su vida y para que la institución educativa vuelva a ser el adalid social que siempre tuvo que haber sido.

Esta tesis es respaldada desde hace muchos años por Freire (197I) cuando planteaba la necesidad de una nueva pedagogía en la que el educando se forme a sí mismo, desarrollando un pensamiento transformador de la realidad, partiendo del análisis y la crítica de situaciones de la vida cotidiana, para lograr liberarse, de esta manera, de la opresión de la pedagogía tradicional, la cual es implementada actualmente en muchas instituciones.

\section{LA PEDAGOGÍA CRÍTICA: \\ UNA OPCIÓN TRANSFORMADORA}

La educación siempre tiene consecuencias sobre la vida de quien la recibe; por esto su rol nunca es neutral, pues modifica en cierta medida nuestras habilidades y nuestra forma de pensar y de expresarnos; sin embargo, a pesar de su importancia, algunas instituciones educativas no tienen claro su proyecto ético y de formación ciudadana, lo que las hace proclives a ir en contravía de las necesidades reales en la actualidad.

Es que al hablar de formación ciudadana no hay que limitarse a lo que sucede o puede suceder en el aula; implica ir más allá, comprometiendo otros contextos sociales y culturales en los que pululan las relaciones interpersonales, donde los cohabitantes de una determinada sociedad intercambian experiencias de vida con base en sus valores, creencias y tradiciones; y es justamente allí, cuando el poder formativo entra a ser protagonista, pues es importante que permee dicha matriz social (valores, creencias, religiones, etc.). Es por eso que formar en la ciudadanía constituye todo un reto pedagógico que se debe fomentar y ser fomentado desde la construcción social, desde la cultura, desde sus mismos actores; es decir, debe ser todo un proyecto cultural, un proyecto social, un proyecto de nación, fundamentado en un imaginario social que se mueva alrededor de lo formativo, de lo individual y de lo colectivo (Mora et al., 2009).

Es por esta razón que las instituciones educativas necesitan edificarse desde la producción de saberes y la promoción de transformaciones, considerando al estudiante como un ser sobre el cual se tiene que dejar huella, impregnándolo de elementos éticos y conocimientos específicos, fundamentados en reglas comunes, socialmente aceptadas, con la intención de permitirle desenvolverse en su contexto. Aquí el docente también tiene un rol determinante, pues es necesario que cumpla la función de transmisor de saberes a través de sus clases.

Todo esto convierte al proceso formativo en un procedimiento de enseñanza-aprendizaje heteroestructurante, concepto usado por De Zubiría (2006), al referirse al proceso formativo como una actividad en la que el estudiante tiene la posibilidad de generar conocimiento y transformar algunos aspectos culturales, incluso en escenarios diferentes al salón de clases. 
Expuesto lo anterior, resulta lógico considerar a la educación como un proceso llamado a reconocer tanto el todo como sus partes, pues solo de esta manera logrará percibir los intereses y las emociones de cada uno de los individuos, de sus interacciones y de su conjunto, y la sociedad y sus sujetos podrán hacer frente a los problemas que actualmente los aquejan.

Es clara, entonces, la relación entre educación, ética, moral, cultura y sociedad; por ello, es un imperativo para las instituciones educativas reflexionar acerca de su reconceptualización, asumiendo sus mea culpa y proponiendo nuevos caminos de transformación. Es así que se puede decir que la educación contemporánea se encuentra ante la exigencia conceptual, social, institucional e histórica de analizar sus perspectivas, con la intención de buscar un nuevo desarrollo, tal como lo exige la actual sociedad global, de tal forma que responda prontamente a los cambios acelerados, constantes y trascendentales que se están viviendo (De Alba, 1998).

En esta misma dirección, es relevante afirmar que actualmente asistimos a una crisis en la que la escuela aún se encuentra en mora de contribuir sustantivamente al cambio, pues las últimas generaciones de estudiantes no han sido formadas integralmente para desempeñarse como sujetos tolerantes, ni mucho menos como individuos capaces de resolver sus conflictos de manera pacífica y, ni siquiera, como ciudadanos fortalecedores de la ética y la democracia.

Es por eso que el nuevo valor de la educación necesita verse desde su capacidad de brindar herramientas que permitan llegar a la tan anhelada reestructuración individual y social, promoviendo en los estudiantes el desarrollo de las competencias básicas y del pensamiento crítico, así como todo lo relacionado con la ética, la moral, la ciudadanía y la cultura.

Por todo lo anterior es que se requiere, desde la escuela, fomentar la ética y la moral, proceso que debe ir de la mano con el crecimiento de las habilidades de pensamiento, permitiéndole al individuo que estudia ser una persona autorregulada, capaz de indagar, pensar, percibir, conocer, juzgar, comparar, abstraer, razonar, opinar, reflexionar, analizar, discutir, examinar, evaluar y comprender por sí mismo, en busca permanente de su crecimiento personal y del desarrollo de su sociedad.

Es por esto que el filósofo francés Michel Foucault consideró al pensamiento crítico como el precursor de la libertad, pues es el que posibilita liberar al individuo de los estereotipos que lo subyugan, permitiéndole asumir posturas diferentes; y es, justamente, este tipo de posturas las que, desde esta reflexión, se promueven, propendiendo porque el estudiante rompa los moldes preestablecidos y asuma una posición activa en su proceso formativo.

Es así como surge la "pedagogía crítica" centrada en el propósito de capacitar a quien aprende para que sea consciente de los condicionamientos que adquiere y de su aplicación en la vida, tanto para él mismo como para la sociedad que lo acoge. De esta forma, la pedagogía crítica puede llegar a producir un cambio importante en la educación tradicional (incluida en ella el componente ético y moral), proponiendo una posición proclive a la experimentación y a la creatividad, y no renuente a los cambios.

Desde esta perspectiva, autores como Villalobos (2014) sugieren que debe existir, necesariamente, una relación dialógica entre los actores que participan en un proceso formativo, pues esto posibilita que se reconozcan entre sí y que juntos exploren otras epistemes, otras alternativas, distintas a las de la pedagogía tradicional.

En esta misma dirección, Gonçalves (2015) plantea que el principal aporte de la pedagogía crítica consiste en que el individuo asuma para sí mismo y para la sociedad un compromiso con la autonomía, convirtiéndose en un sujeto analítico, pensante y capaz de tomar decisiones por sí mismo, con base en los elementos dados en su formación, tanto en el aula como fuera de ella.

Como se puede apreciar, la toma de conciencia acerca de la importancia de la pedagogía crítica a través de los años (Cascante y Martínez, 20 I 3) y en la formación de hoy (Ortega, 20l4), reside en que dicha pedagogía brinda la posibilidad de potenciar en el individuo que se forma su capacidad discursiva, mostrándole cómo llevar conscientemente a la práctica lo teóricamente aprendido, replanteando sus propias acciones, reflexionando permanentemente, movilizándolo política y socialmente y dinamizando sus capacidades, para permitir, de esta forma, la resignificación de su proceso educativo y la transformación de su contexto.

\section{Pero, icómo puede ser un CURRÍculo PERTINENTE PARA LA FORMACIÓN \\ EN CIUDADANÍA?}

Para contestar esta pregunta, se sugiere que todos los aspectos aquí abordados confluyan en la relación educación - ética y moral - formación ciudadana. Por 
ello, se propone que se construya, desde la escuela, un nuevo currículo que permita formar a los estudiantes en cultura ciudadana, que involucre en el aula temas relacionados con los problemas de la vida diaria y de la sociedad misma, que promueva la práctica de valores cívicos y la reflexión crítica, que fortalezca las relaciones interpersonales, que fomente la investigación y la indagación, y que tenga como eje fundamental al estudiante, visto este como un sujeto ávido de aprendizaje y dispuesto a aportar socialmente.

Un currículo con perspectiva democratizadora, descentralizado, que sea autónomo y que permita la autonomía, que garantice la preparación para la acción social, que invite a la construcción de significados y contenidos, que promueva la creatividad, que proponga transformaciones importantes en la cultura escolar y, al mismo tiempo, que se preocupe por el impacto de sus contenidos en la sociedad.

Y este currículo, a su vez, debe formar parte de una nueva educación, plagada de variables, de conocimientos divergentes, de múltiples matices, pero ávida de ser nuevamente protagonista de una evolución humana consciente, en la que el individuo sea capaz de transformarse y adaptarse a los cambios de manera permanente.

\section{A MODO DE COLOFÓN: UNA CULTURA CONVIVENCIA CIUDADANA Y PAZ PARA UNA COLOMBIA MEJOR}

Para cerrar con esta reflexión, se debe decir que Colombia es y ha sido un territorio marcado por la violencia a lo largo de su historia; es por esto que todo lo expresado en este artículo intenta convertirse en una posibilidad de solución para diezmar dicha violencia, insistiendo en el replanteamiento de la práctica pedagógica y de la revisión y el análisis de la influencia de dicho proceso formativo en la sociedad.

Por esta razón, se hace un llamado para que se piense en la transformación de dicha práctica y qué mejor oportunidad que el episodio coyuntural que se vive, en el que la paz surge como una solución propuesta desde el propio Estado; por ello, es necesario pensar en la revisión, organización y formulación de un nuevo currículo en el que la paz, promovida desde la convivencia ciudadana, sea un valor innato y cotidiano, un eje central de convivencia y un aspecto promotor de la transformación del tejido social.
Pues bien lo dicen Chaux, Lleras y Velásquez (2004): formar para la ciudadanía es fundamental hoy en día en cualquier sociedad del mundo, siendo mucho más necesario y urgente en el contexto colombiano, donde la violencia, la corrupción, la inequidad y otros múltiples problemas sociales, asociados con la ausencia de ética y valores, tanto individuales como colectivos, son evidentes a diario.

Por ende, se requiere prontamente de un nuevo currículo en el que se refleje la comprensión del otro, la solución pacífica e inteligente de conflictos, la conciliación, la aceptación y la valoración de las diferencias, el reconocimiento de la diversidad, la toma de conciencia y la responsabilidad social, entre otros aspectos, pues estas deben ser las bases para fomentar una cultura de paz, de convivencia, desde la escuela, en procura de un verdadero cambio social (Morillas, 2006).

De este modo, la educación puede llegar a formar nuevos ciudadanos, nuevas generaciones de colombianos, reconocedores de sus derechos, pero también de sus deberes y responsabilidades. Es por esto que la educación en Colombia debe aprovechar el momento, la efervescencia del proceso de paz que se vive, para asumir el desafío, aunar esfuerzos y pensar y promover, desde la escuela, una real cultura de paz y convivencia, pues este es el mejor legado que se le puede dejar a las siguientes generaciones.

\section{CONCLUSIONES}

La formación ciudadana necesita ser un componente perenne en la escuela, que permee todos sus contenidos, tanto a nivel individual como colectivo; por ende, se requiere que el currículo, los planes de estudio, la práctica pedagógica y demás componentes formativos, propicien y fomenten los aspectos ético y moral, tan importantes en la estructuración y conformación de la cultura ciudadana.

Es así como todos los implicados en el proceso de formación (estudiantes, docentes, directivos, familiares, etc.) deben comprometerse con esta consigna y velar porque el aula se convierta en un espacio de respeto, tolerancia y solidaridad, donde el estudiante pueda asumir una postura ética y moral, activa y crítica frente a su realidad y la de quienes le rodean, aprendiendo a vivir tranquilamente y de manera natural en sociedad.

Todo esto posibilitará que cohabiten en un mismo espacio la educación, la ética, la moral y la formación 
ciudadana, brindándole al país futuras generaciones, nuevos ciudadanos, con principios y valores que, aunados, puedan llevar, por fin, a la conformación de una nueva Colombia en paz, caracterizada por la sana convivencia \&

\section{Referencias bibliográficas}

Aguilar, J. M., Alías, A., Álvarez, J., Fernández, J. M., Pérez, E. R. y Hernández, A. I. (2015). Necesidades de formación del profesor universitario en competencias relacionadas con la acción tutorial. Docencia Universitaria, I3(3), 357-375.

Bauman, Z. (2009). Los retos de la educación en la modernidad líquida. Madrid: Gedisa.

Cascante, C. y Martínez, J. (20I3). Pedagogía crítica, treinta años después. Revista Interuniversitaria de Formación del Profesorado, 27(2), |5-2|.

Chaux, E., Lleras, J. y Velásquez, A. M. (2004). Competencias ciudadanas: De los estándares al aula. Una propuesta de integración a las áreas académicas. Recuperado el 18 de diciembre de 2015, de http://www.colombiaaprende.edu.co/html/mediateca/1607/articles-75077_ archivo.pdf

Cortina, A. (2002). Educación en valores y responsabilidad cívica. Bogotá D. C., Colombia: El Buho.

Cortina, A. (2009). Ciudadanos del mundo: Hacia una teoría de la ciudadanía. Madrid: Alianza.

Crocker, D. (2008). Ethics of global development: Agency, capability and deliberative democracy. Cambridge: Cambridge University Press

De Alba, A. (1998). Currículum: Crisis, mito y perspectivas. Buenos Aires: Miño y Dávila.

Declaración Universal de los Derechos Humanos (ONU, 1948)

De la Rosa, B. (1977). Educación cívica y comprensión internacional. Barcelona: CEAC.

De Oliveira, R. S. (2014). Ética na escola: Por uma abordagem argumentativa. Educação, 37(3), 454-462.

De Zubiría, J. (2006). Los modelos pedagógicos: Hacía una pedagogía dialogante (2ª . Ed.). Bogotá, D. C: Magisterio.

Delors, J. (1996). La educación encierra un tesoro. Madrid: Santillana, Unesco.

Flórez, R. (1994). Hacia una pedagogía del conocimiento. Bogotá D. C.: McGraw Hill.

Freire, P. (197I). Conciencia, crítica y liberación: Pedagogía del oprimido. Bogotá D. C.: Camilo.

Gómez, C. J., Miralles, P. y Molina, S. (2015). Evaluación, competencias históricas y educación ciudadana. Revista de Estudios Sociales, 52, 9-13.

Gonçalves, M. (20I5). Educação e ambiguidades da autonomização: Para uma pedagogia crítica da promoção do indivíduo autónomo. Revista Brasileira de Educação, 20(63), 995-1008.

Hobbes, T. (1999). Leviatán o la materia, forma y poder de un estado eclesiástico y civil. Madrid: Alianza.

Ministerio de Educación Nacional -MEN. (2006). Estándares básicos de competencias en Lenguaje, Matemáticas, Ciencias y Ciudadanas. Bogotá D. C., Colombia: MEN.

Mora, R., Ripoll, M., Robles, C., Méndez, Z. y Vesga R. (2009). Prácticas curriculares, cultura y proceso de formación. Educación y Humanismo, 16, I2-21. 
Morillas, M. D. (2006). Competencias para la ciudadanía: Reflexión, decisión, acción. Madrid: Narcea.

McLuhan, C. y Powers, B. R. (2002). La aldea global. Barcelona: Gedisa.

Ortega, P. (2014). Pedagogía crítica en Colombia: Un estudio en la escuela de sectores populares. Sophia, 10(2), 50-63.

Ortiz, M. G. (20I4). El perfil del ciudadano neoliberal: La ciudadanía de la autogestión neoliberal. Sociológica, 29(83), 165-200.

Restrepo, J. A. y Echavarría, C. V. (20I3). Correlatos morales y políticos de las prácticas ciudadanas de un grupo de jóvenes adscritos al programa Clubes Juveniles Comunitarios de la ciudad de Manizales. Eleuthera, 8, 56-79.

Ripoll, M. y Méndez, Z. (20II). La cultura de la legalidad, una propuesta para desarrollar las competencias ciudadanas en la Institución Educativa Técnico Industrial Blas Torres de la Torre del municipio de Soledad, Atlántico (Tesis de maestría). Universidad Simón Bolívar, Barranquilla, Colombia.

Torney, J., Lehmann, R. Oswald, H. y Schulz, W. (199I). La educación cívica y ciudadanía: Proyecto de educación cívica de la IEA. Londres: IEA.

Villalobos, D. C. (2014). Planteamientos pedagógicos relacionados con las ciudadanías propias en la pedagogía crítica de Paulo Freire. El Ágora USB, I5(I), 195-215.

Villarroel, R. (2013). Ética del desarrollo, democracia deliberativa y ciudadanía biológica: Una articulación en clave biopolítica. Revista de Filosofía, 29, 257-276

Westbrook, R. B. (1999). John Dewey (1859-1952). Recuperado el 24 de enero de 2016, de http://www.unav.es/gep/Dewey/Westbrook. pdf

Zambrano, E., Fernández, F., Rivera, A. y Zapata, E. (20l4). Construcción y validación de un instrumento para medir las competencias ciudadanas en estudiantes universitarios. Zona Próxima, 21, 78-97.

Zapata, J. J. y Villa, V. (20I0). La formación de los nuevos profesionales. Medellín: Universidad de Antioquia. 